\title{
SCIDoC
}

International Journal of Forensic Science \& Pathology (IJFP)

ISSN: 2332-287X

\section{Renal Histo-Pathological Changes On Autopsy In Pregnancy Related Deaths}

Research Article

Pratima Khare*, Renu Gupta, RajaniAnand, Avni Bhatnagar, Zini Chaurasia

Pathology, Dr Baba Saheb Ambedkar (BSA) Medical College and Hospital, New Delhi, India.

\section{Abstract}

Introduction: Medico-legal autopsies confirm the immediate cause of death and final diagnosis. These also provide additional information about the state of various vital organs of the body and existing co-morbidities that could have affected the outcome of the patients. Not much data is available on incidence of Biopsy/ autopsy proven cases of renal pathology in pregnant/ pregnancy related deaths.

Aims: The study aimed at finding out prevalence and pattern of various types of renal pathologies and their co-relation with various pregnancy related causes leading to death where autopsies were performed.

Material \& Methods:The study consisted of eleven cases of autopsies conducted on cases of deaths of pregnant ladies who died having medicolegal problems or alleged medicolegal negligence. The kidney tissue specimens were fixed in $10 \%$ formal saline for 48-72 hours before processing. H\&E stains and PAS stain were performed on sections from paraffin blocks.

Results: The study demonstrated renal changes in a very high percentage of cases, which were mostly related to the ongoing pre-existing disease processes contributing towards cause of death. Conditions like eclampsia were associated with hydropic changes in kidney. Similarly, deaths due to hemorrhagic shock were associated with acute tubular necrosis/ hydropic changes in the kidney. Non-gestational causes of death like disseminated tuberculosis was also associated with renal tuberculosis.

Conclusions: The Physician must be aware of the high prevalence and wide spectrum of possible pathologies in the kidney related to various obstetrical complications. The focus should be to develop more efficacious diagnostic methods for timely intervention.

Keywords: Autopsy; Maternal Deaths; Renal Pathology; Eclampsia; Acute Tubular Necrosis (ATN).

\section{Introduction}

Medico-legal autopsies and clinical autopsies, beside confirming the immediate cause of death and making final diagnosis, also provide additional information about complications of intensive care and information about existing co-morbidities that could have affected the outcome of the patient. Thus, an autopsy also serves as important tool for retrospective quality assessment of the clinical diagnosis and is educational tool to the clinician [1].

Not much data is available on incidence of Biopsy/autopsy proven cases of renal pathology in pregnant/pregnancy related deaths. In practice, renal biopsies are rarely performed serially and practically never on control obstetric patients without proteinuria or hypertension, or on those with symptoms suggesting imminent eclampsia. Furthermore, because specimens are small, and lesions may involve only a few glomeruli, they may be missed. Last, in some instances, the technique may lead to crush or traction artefacts [2]. Chandrakar S.et.al. in their post mortem study on maternal deaths observed renal pathology in $25.3 \%$ of autopsies, which contributed to a significant number of maternal mortalities and morbidities [3]. In autopsy, the kidneys are examined for disease, injury and other related changes suggesting cause of death or the incidental findings in many situations. Since kidney biopsy is usually avoided in critically ill patients, postmortem histologic evaluation of kidneys may be the first and only opportunity to identify these diseases [4].

\section{Material and Methods}

The present retrospective study was conducted in the department of pathology at our institute. It included all the post-mortem

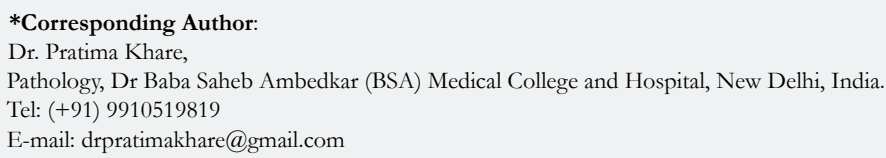

Copyright: Dr. Pratima Khare ${ }^{\complement} 2021$. This is an open-access article distributed under the terms of the Creative Commons Attribution License, which permits unrestricted use, distribution and reproduction in any medium, provided the original author and source are credited. 
cases of deaths related to pregnancy with legal issues including cases of medical neglect, since Oct. 2013 to May 2021. In view of the medicolegal nature and legal bonding as per law of the land, no ethical clearance for carrying out the autopsy was required. During the said period 11 autopsies of pregnant ladies were carried out which consisted of those who died having medicolegal problems or alleged medicolegal negligence. The autopsy time varied from one day to two days depending upon receiving of dead body in the autopsy surgical theatre. The kidney tissue specimens were fixed in 10\% formal saline for 48-72 hours before processing. H\&E stains were performed on sections from paraffin blocks in all cases.

The clinical data included patient's age, antenatal history wherever available, clinical presentation in cases of the institutional deaths, contributing cause of death, probable time interval between death and post-mortem, and state of important organs like lung and liver, besides kidney at the time of post-mortem. The tissue/ whole organ sample were received in 10\% formal saline. Sections were taken for further processing and histo-pathological examination of the renal tissue. The staining agent used in most cases was H\&E. PAS stain was used wherever required.

\section{Results}

There were five cases of direct "Gestational death" (3 cases of eclampsia, 1 case of ruptured tubal ectopic pregnancy, 1 case of illegal medical termination of pregnancy (MTP) with ruptured uterus, bleeding and shock. [Table]. There were 3 cases of "indirect gestational deaths" (1 case of home delivery with post-partum hemorrhage $(\mathrm{PPH})$, one case of post lower segment caesarean section (LSCS) with Pulmonary embolism and 1 case of acute abdomen at 7 months of gestation. There was 3 case of "nongestational death" (one case of death due to TB in 8 months pregnant lady and 2 cases of 8 months pregnant females dying under mysterious circumstances where no obstetrical cause could be ascertained). The series had $9(81.8 \%)$ cases in the 3 rd trimester of pregnancy, whereas 1 each in 1 st and 2 nd trimester. At least 8 cases $(72.72 \%)$ cases were attributed to direct and indirect gestational causes. There were $7(63.33 \%)$ cases of institutional death whereas 4 cases $(36.36 \%)$ were those which were brought dead to the hospital.

Focal hydropic changes in the tubules were seen in 5 cases [Fig 1]. Etiology among them were ruptured ectopic tubal pregnancy in one case, eclampsia in three cases and one case where LSCS was performed for eclampsia with intra uterine death(IUD) of fetus. There were 3 cases of acute tubular necrosis [Fig 2]. Two of these were attributed to PPH (One case death due to PPH following home delivery of a still born baby) and the second case of death (due to Post MTP ruptured uterus associated with hemorrhagic shock). One case of ATN was seen in a case where the primary cause of death was eclampsia.

There was 1 case of renal tuberculosis in an eight months pregnant lady suffering from disseminated tuberculosis [Fig 3]. The renal pathology showed one case of partial to complete glomerulo- sclerosis with basement membrane thickening in a case [Fig 4] where the primary cause of death was attributed to Post-partum pulmonary embolism post LSCS surgery. In 1 case of death of 7 months pregnant lady due to acute abdomen, no remarkable change was detected on histopathological examination of kidney.

\section{Discussion}

Figure 1. Hydropic degeneration in the Tubules [H\&E stain 10x20].

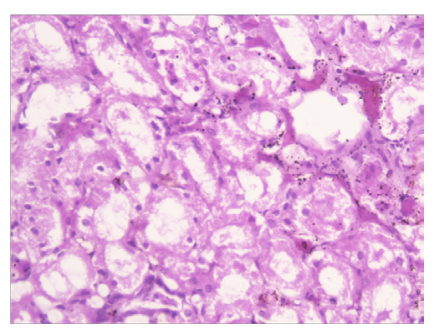

Figure 2. Acute Tubular Necrosis [H\&E stain 10x20].

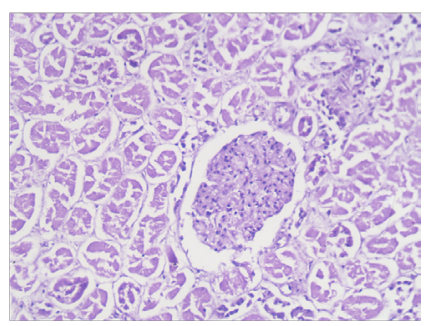

Figure 3. Granuloma and Chronic Inflammatory cell infiltrate in Kidney Tissue [H\&E stain 10x20].

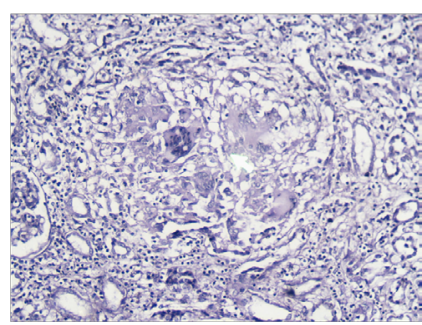


Figure 4. Nodular Sclerosis and Basement membrane thickening of the Glomeruli [ PAS stain 10x20].

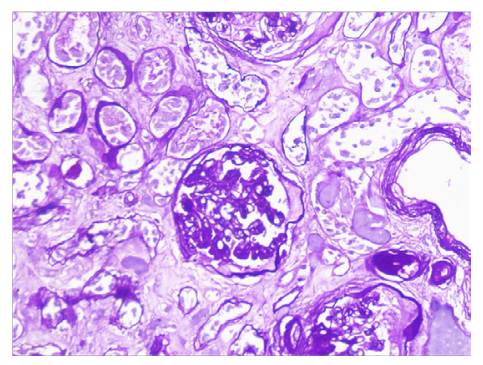

Table. Renal Lesions seen on Autopsy in Maternal deaths ( $n=11)$.

\begin{tabular}{|c|c|c|c|c|c|}
\hline S.No. & Age & $\begin{array}{c}\text { "Direct Gestational } \\
\text { Death }\end{array}$ & $\begin{array}{c}\text { Indirect Gestational } \\
\text { Death }\end{array}$ & $\begin{array}{c}\text { Non-Gestational } \\
\text { Death. }\end{array}$ & $\begin{array}{c}\text { Pathologic abnormalities of } \\
\text { Kidney }\end{array}$ \\
\hline 1 & 29 & Ectopic Pregnancy & -- & -- & $\begin{array}{c}\text { Hydropic Degeneration in } \\
\text { Tubules }\end{array}$ \\
\hline 2 & 32 & Eclampsia & -- & -- & $\begin{array}{c}\text { Hydropic Degeneration in } \\
\text { Tubules }\end{array}$ \\
\hline 3 & 25 & $\begin{array}{l}\text { MTP, ruptured uterus, } \\
\text { bleeding \& shock }\end{array}$ & -- & -- & Acute Tubular necrosis \\
\hline 4 & 22 & -- & $\begin{array}{c}7 \text { month pregnant, acute } \\
\text { abd pain }\end{array}$ & -- & No remarkable pathology \\
\hline 5 & 28 & $\begin{array}{l}9 \text { month pregnant with } \\
\text { Eclampsia with IUD }\end{array}$ & -- & -- & $\begin{array}{c}\text { Hydropic Degeneration in } \\
\text { Tubules }\end{array}$ \\
\hline 6 & 28 & -- & -- & $\begin{array}{l}\text { Known case of Pul- } \\
\text { monary TB,(home } \\
\text { delivery death) }\end{array}$ & Multiple granuloma \& necrosis \\
\hline 7 & 34 & -- & -- & $\begin{array}{l}8 \text { month pregnant } \\
\text { found under myste- } \\
\text { rious circumstance }\end{array}$ & $\begin{array}{l}\text { Hydropic degeneration in tu- } \\
\text { bules and congestion }\end{array}$ \\
\hline 8 & 25 & -- & Post LSCS, & -- & $\begin{array}{l}\text { Occasional Hyper-cellular glom- } \\
\text { eruli, Diffuse basement mem- } \\
\text { brane thickening, diffuse nodular } \\
\text { glomerular sclerosis. Interstitial } \\
\text { chronic inflammatory infiltrate. }\end{array}$ \\
\hline 9 & 23 & -- & -- & $\begin{array}{l}8 \text { months brought- } \\
\text { dead }\end{array}$ & $\begin{array}{c}\text { Hydropic Degeneration in } \\
\text { Tubules }\end{array}$ \\
\hline 10 & 22 & Eclampsia & -- & -- & $\begin{array}{c}\text { Congestion and feature of Acute } \\
\text { Tubular necrosis }\end{array}$ \\
\hline 11 & 28 & -- & $\begin{array}{l}\text { Home delivery, still born } \\
\text { baby followed by PPH } \\
\text { (Brought Dead) }\end{array}$ & -- & Acute tubular necrosis \\
\hline Total & & 5 & 3 & 3 & 11 \\
\hline
\end{tabular}

Pregnancy-related death is defined by the International Classification of Diseases, Tenth Revision (ICD-10) as the death of a woman while pregnant or within 42 days of termination of pregnancy, irrespective of the cause of death [5]. The incidence of autopsy, being carried out after maternal deaths during perinatal period from pregnancy-related or other causes, remains an uncommon event in routine forensic autopsy practices. We had 11 such cases since the inception of autopsy services at our institute from Oct, 2013 till May, 2021.

The common causes of maternal death vary somewhat from region to region and include pulmonary thromboembolism, amniotic fluid embolism, primary postpartum uterine hemorrhage, infection, and complications of hypertension including preeclampsia and eclampsia. Pulmonary disease, complications of anesthesia, and cardiomyopathy also are significant contributors to maternal mortality in some populations [5]. Buschmann, C. et al.[4] reviewed medico-legal records in Berlin, from 2005 to 2010 for all female deaths due to maternal and pregnancy-related causes, including deaths of pregnant women from non-natural causes. Fatalities were classified as "direct gestational death," "indirect gestational death" or "non-gestational death." There were total 13 female fatalities. Eight $(61.5 \%)$ women died in-hospital, four $(30.8 \%)$ at home, and one woman died in public. Their series had three cases were of "non-gestational deaths," six cases of "direct gestational deaths," and two cases of "indirect gestational deaths." The cause in one of their case remained unclear after au- 
topsy and additional examinations. The case of death in another one case seemed to be directly related to previous gestation. Our series of 11 cases also had the similar pattern with $5(45.45 \%)$ cases of direct gestational deaths and 3 cases $(27.27 \%)$ cases of indirect gestational deaths. Among the 3 cases of non-gestational death,1 $(9.09 \%)$ died of disseminated tuberculosis whereas in 2 cases of crime, death was not related to gestation. Similar to the series of Buschmann [4], our series also had $63.63 \%$ of the cases of institutional deaths. However, Chandrakar S et.al. [3] in their study of 42 autopsies in pregnant females reported having 10 $(23.8 \%)$ patients presenting in the second trimester; $14(33.3 \%)$ in the third trimester; and $18(42.8 \%)$ in the postpartum period. We had only 2 cases in 1 st and 2 nd trimester whereas rests of the cases $(81.8 \%)$ were in 3rd trimester. Their series had 37 patients $(88 \%)$ who died due to indirect causes of maternal mortality (predominantly infections), and 5 patients $(12 \%)$ died due to direct causes of maternal death (e.g. placenta abruption, pregnancyinduced hypertension, ruptured ectopic pregnancy). Our figures could not be compared with their series apparently because of the different parameters used for making the sub groups.

On microscopy, Chandrakar et al [3] reported that kidney showed evidence of Acute tubular necrosis 22 cases, Acute pyelonephritis 7 cases, Disseminated intravascular coagulation 7 cases, Diabetic nephropathy 3 cases, Sickle cell nephropathy 1 case, Thrombotic microangiopathy 1 case and Tuberculosis of kidney 1 case. However, in their series no attempt was made to correlate histo-pathological findings with cause of death.

In our series of 11 autopsies in pregnant ladies, 5 cases had focal hydropic changes in the tubules [Fig1] in the kidney. This included 2 cases dying of eclampsia, one case dying due to ruptured ectopic tubal pregnancy with secondary shock and 2 cases of 8 months pregnant lady dying under mysterious circumstances. One of those two homicidal deaths, one had additional congestive changes in the renal tissue signifying hypoxic injury.Hydropic change refers to accumulation of water in the cells and is one of the early signs of cellular degeneration in response to injury. In tubules it is due to accumulation of water in the tubular cells usually due to hypoxia of tissues with resultant decrease in aerobic respiration in mitochondria and decrease production of ATP. Presence of hydropic changes in renal tubules in cases of toxemia pregnancy was also reported by Sheehan [2]. They believed that the characteristic changes in toxemia are the thickening of the epithelium due to a massive increase of the cytoplasm (Hydropic changes). Richard [6] in his classic study in 1967 on casualties of Korean War found renal changes in 33\% cases. They demonstrated a close clinical association of a major hypotensive episode with the subsequent development of renal injury and failure. The study demonstrated that the condition leading to shock may also lead to hydropic changes in the kidney.In our series, the case with shock after ruptured ectopic tubal pregnancy had hydropic changes in the renal tissue,pointing towards the hypotensive episodes (Shock) being the etiological factor for those changes. Both the suicide/homicide deaths in our series had hydropic changes in the renal tissue suggestive of hypoxic injury being responsible for those changes. Congestive changes present in one of these two suicide/ homicide case are a common feature found in kidney as well as many other vital organs as reported by many authors [7].

Three cases in our series had features of acute tubular necrosis [Fig 2]. The hypovolemic/hemorrhagic shock leading to ATN is an established cause of ATN. Among those 3 cases with ATN in our series, one case died of PPH, one due to hemorrhagic shock following MTP with ruptured uterus bleeding and shock, one case where death was a complication of eclampsia.Chandrakar et.al [3] also observed that obstetric complications, such as abruptioplacentae, septic abortion, eclampsia, postpartum hemorrhage, and puerperal sepsis, are the most common causes of renal cortical necrosis (50\%-70\%). Many authors have reported ATN in eclampsia. Pollak [8] says that an intense vasospasm is characteristic of preeclampsia and eclampsia and could be a contributing factor for renal changes. However, Sheehan [2] believed that there were never any ischemic lesions in the kidney in uncomplicated toxemia and histologic evidence of an extremely focal arrest of circulation is rare and can be found in a few cases of eclampsia or toxemic crisis. We had histopathological evidence of these changes, one case dying of complication of eclampsia, suggestive of toxemic crisis playing a role in the deaths.

There was one case of Post LSCS death in our series. It was a case of un- booked pregnancy and no antenatal records were available. The surgery was done for fetal distress. The primary cause of death of the mother was pulmonary embolism. The renal tissue on autopsy showed features of hyper-cellular glomeruli, diffuse nodular sclerosis and basement membrane thickening [Fig 4]. Sheehan [2] in his study of renal morphology in preeclampsia reported glomerular size increases in the eclampsia group. In posteclampsia, there may be a further increase in size, but their data are insufficient for valid calculations. The number of glomeruli involved is very variable from a few to several glomeruli in a section. The glomerular lesion is common in severe toxemia and eclampsia but is not absolutely pathognomonic. The basement membrane which is normally about $0.3 \mathrm{~cm}$ in thickness may be more thickened. It is commonly accepted that one of the typical changes in toxemia is a hypertrophy of the media of afferent arterioles. This is not in accord with observations by Sheehan [2]. About $20 \%$ of patients with fatal eclampsia have acute intravascular hemolysis. Jonathan et.al.[9] described lesions from autopsies of women who died of eclampsia, showed presence of glomerular endotheliosis. Pathological changes in cases of eclampsia include widespread endothelial/vascular injury in vulnerable organ beds.

Chunhong Huang and Shanying Chen reported $0.81 \%$ incidence rate of AKI (acute kidney injury) during pregnancy and puerperium [10]. Their series had three hundred and forty-three cases of AKI during pregnancy and puerperium included 21 severe AKI cases and 21 cases with acute-on-CKD (Chronic kidney disease). Pre-eclampsia/eclampsia, and postpartum hemorrhage were the most frequent causes of AKI during pregnancy and puerperium. Our observations based on histopathological evidence of renal injuries in deaths associated with eclampsia, PPH (Post partem hemorrhage) and shock are similar to the observations of Chunhong et.al [10].

Many authors believe that incidence of acute renal failures are rare in modern times due to improved medical care, decrease in the number of septic abortions, effective care of obstetrical complications, and legalization of abortion [11, 12]. Still the risk remains in illegal abortions and unsupervised home deliveries. AKI during pregnancy and puerperium is not as rare as we thought. Amniotic fluid embolism and postpartum hemorrhage are the leading causes of maternal mortality. Severe AKI may predict 
poor outcome.In our series, one case of post LSCS death was proved having died of pulmonary embolism.

Many authors believe that pulmonary and extra-pulmonary TB affects a pregnant lady in the same way as it affects non- pregnant lady. Depending upon various factors such as site and extent of disease, stage of pregnancy, nutritional status, presence of concomitant diseases, the immune status and co-existence of HIV infection, the prognosis may vary [13-15]. There was only 1 case of renal tuberculosis[ Fig 3] in an eight months pregnant lady suffering from disseminated tuberculosis in the series. Renal tuberculosis has been reported to the extent of $27 \%$ in cases of disseminated tuberculosis [16] and is often missed clinically by treating physician. Both treating physician and forensic pathologist must be aware of the possibility.

Among the two cases where autopsy was carried out on suspicion of suicide/homicide, in one case of hydropic degeneration in tubules and congestion was detected whereas in the other case only signs of hydropic degeneration were present. The congestive changes is a very common phenomenon seen in various body organs in cases of suicide/homicide due to strangulation as has been reported by many authors [7].

\section{Conclusion}

In summary, the study demonstrated that renal changes are very common on autopsies performed on pregnant patients. These changes are mostly related to the ongoing disease process contributing towards causes responsible for the death whether due to gestational or post gestational causes. The treating gynecologist must be aware of possibilities of renal complications of diseases associated with pregnancy. Non- gestational causes are usually associated with serious systemic diseases like disseminated tuberculosis or homicidal/suicidal reasons. The pathologist must have a broad knowledge of the physiological and biochemical changes that occur during pregnancy, as well as the clinical and pathological manifestation of these changes. In addition, it should be kept in mind that deaths during pregnancy may be due to unnatural causes. Accident, homicide, and suicide must be ruled out in each case.

\section{References}

[1]. Nadesan K. The importance of the medico-legal autopsy. Malays J Pathol. 1997 Dec;19(2):105-9. Pubmed PMID: 10879249.

[2]. HSheehan HL. Renal morphology in preeclampsia. Kidney international. 1980 Aug 1;18(2):241-52.

[3]. Chandrakar S, Padmanabhan A. Renal pathology in maternal deaths: An autopsy study. Indian Journal of Pathology and Oncology. 2018 Jul;5(3):40510 .

[4]. Buschmann C, Schmidbauer M, Tsokos M. Maternal and pregnancy-related death: causes and frequencies in an autopsy study population. Forensic Sci Med Pathol. 2013 Sep;9(3):296-307. Pubmed PMID: 23275021.

[5]. Christiansen LR, Collins KA. Pregnancy-associated deaths: a 15-year retrospective study and overall review of maternal pathophysiology. Am J Forensic Med Pathol. 2006 Mar;27(1):11-9. Pubmed PMID: 16501342.

[6]. Dow RW, Fry WJ. Hemorrhagic shock. Changes in renal blood flow and vascular resistance. Arch Surg. 1967 Feb;94(2):190-4. Pubmed PMID: 6016265.

[7]. Pathak A, Mangal HM. Histo-Pathology Examination in Medico-legal Autopsy Pros \& Cons. Journal of Indian Academy of Forensic Medicine. 2010;32(2):128-31.

[8]. VE Pollak: Preeclampsia and kidney disease; CH Coggin, NV Cummings (Ed), Washington, Prevention of Kidney and Urinary Tract Diseases, Health Department Ed Welfare Publication, Washington DC0, 1978: 95-132.

[9]. Hecht JL, Ordi J, Carrilho C, Ismail MR, Zsengeller ZK, Karumanchi SA, et al. The pathology of eclampsia: An autopsy series. Hypertens Pregnancy. 2017 Aug;36(3):259-268. Pubmed PMID: 28678644.

[10]. Huang C, Chen S. Acute kidney injury during pregnancy and puerperium: a retrospective study in a single center. BMC Nephrol. 2017 May 1;18(1):146. Pubmed PMID: 28460634.

[11]. Prakash J, Kumar H, Sinha DK, Kedalaya PG, Pandey LK, Srivastava PK, Raja R, Usha. Acute renal failure in pregnancy in a developing country: twenty years of experience. Ren Fail. 2006;28(4):309-13. Pubmed PMID: 16771246.

[12]. Arora N, Mahajan K, Jana N, Taraphder A. Pregnancy-related acute renal failure in eastern India. Int J Gynaecol Obstet. 2010 Dec;111(3):213-6 Pubmed PMID: 20870228.

[13]. Sivakumar V, Sivaramakrishna G, Sainaresh VV, Sriramnaveen P, Kishore CK, Rani ChS, Jagadeesh K. Pregnancy-related acute renal failure: a ten-year experience. Saudi J Kidney Dis Transpl. 2011 Mar;22(2):352-3. Pubmed PMID: 21422644.

[14]. Dragun D, Haase M. Acute kidney failure during pregnancy and postpartum. InManagement of Acute Kidney Problems 2010; 445-458.

[15]. Good JT Jr, Iseman MD, Davidson PT, Lakshminarayan S, Sahn SA. Tuberculosis in association with pregnancy. Am J Obstet Gynecol. 1981 Jul 1;140(5):492-8. Pubmed PMID: 7246682.

[16]. Daher Ede F, da Silva GB Jr, Barros EJ. Renal tuberculosis in the modern era. Am J Trop Med Hyg. 2013 Jan;88(1):54-64. Pubmed PMID: 23303798. 